DOI: 10.12957/demetra.2016.23541

\title{
Feijoada e Samba: análise contextual em uma agremiação no subúrbio carioca
}

\section{Feijoada and Samba contextual analysis: in an association in a suburb in Rio de Janeiro}

\author{
Gabriella Fernandes Gachet ${ }^{\top}$ \\ Marta Maria Antonieta de Souza Santos' \\ Mirian Ribeiro Baião? \\ 1 Universidade Federal do Rio de Janeiro, \\ Instituto de Nutrição Josué de Castro. Rio de \\ Janeiro-RJ, Brasil. \\ Correspondência / Correspondence \\ Gabriella Fernandes Gachet \\ E-mail: gabriella_gachet@yahoo.com.br
}

\section{Resumo}

O estudo tem como objetivo analisar o contexto sociocultural do binômio feijoada e samba no Cacique de Ramos, agremiação com 54 anos de tradição na propagação do samba de raiz, no subúrbio carioca. O estudo se valeu de uma aproximação com a Hermenêutica de Profundidade (HP) de Thompson (2011) com vistas à construção da análise sócio-histórica (ASH). Os dados foram obtidos a partir da observação livre, de entrevistas formais e informais e de pesquisas na internet. Os elementos que compõem a ASH foram organizados e tratados como categorias analíticas, a partir de uma adaptação da análise de conteúdo de Bardin (1977). Os resultados apontaram que o Cacique é um ícone de resistência e divulgação do samba carioca, sendo motivo de admiração e orgulho para seus frequentadores e vizinhos da quadra. Envolta em misticismo, a tamarineira tornou-se um símbolo de identidade, assumindo significado de elemento quase sagrado, de respeito, bênção e sorte. As interações entre frequentadores, vizinhos, comerciantes e o Cacique de Ramos revelam as mais diversas relações de poder e transmissão de valores entre esses sujeitos. A feijoada, além de agregar simbolismo e servir como recurso de difusão da tradição cultural, também contribui para manter vivas as rodas de samba e a agremiação.

Palavras-chave: Pesquisa qualitativa. Alimentação. Cultura. Música. Hermenêutica. 


\section{Abstract}

The study aims to analyze the sociocultural context of the dyad feijoada and samba in Cacique de Ramos, an association with 54 years of tradition in disseminating the traditional samba in the suburb in Rio de Janeiro. The study has drawn upon Depth Hermeneutics (DH) of Thompson (2011) with a view to the development of socio-historical analysis (SHA). Data were collected by means of free observation, formal and informal interviews, and internet searches. The elements that compose SHA were organized and treated as analytical categories, based on an adaptation of content analysis of Bardin (1977). The results pointed out that Cacique is a symbol of resistance and dissemination of samba carioca (from Rio), and it is the pride and joy of people who participate in and live next to the block. Shrouded in mysticism, the tamarind tree has become a symbol of identity, taking on the meaning of an almost sacred element, respect, blessing and good luck. The interactions among blockgoers, neighbors, traders and Cacique de Ramos reveal the several power relations and the transmission of values among these subjects. Feijoada not only adds symbolism, but also serves as a resource of dissemination of cultural tradition, and helps to keep alive the samba circles and the association.

Key words: Qualitative Research. Feeding. Culture. Music. Hermeneutics.

\section{Introdução}

O samba foi influenciado pela cultura das diferentes etnias que compõem o povo brasileiro. Começou a ser reproduzido no Rio de Janeiro após a vinda de ex-escravos, principalmente da Bahia, para a cidade..$^{1-3}$

O samba, que nas primeiras décadas do século XX, era tocado apenas nos redutos negros da cidade, principalmente na região do cais do porto e na casa das "tias baianas", mulheres que tinham grande respeito dentro da comunidade, ganhou destaque por volta da década de 1940, com a popularização do rádio e a ascensão de compositores, como Noel Rosa, que levaram o ritmo para as classes mais abastadas da sociedade carioca.,

A culinária brasileira, assim como o samba, também foi construída pela miscelânea de hábitos europeus, indígenas e africanos. Câmara Cascudo ${ }^{5}$ dá diversos exemplos de como as práticas culinárias dessas diversas etnias foram forjando a comida no país, desde o início da sua colonização. 
A feijoada, hoje considerada um prato típico do Brasil, ${ }^{6}$ também foi sendo reconstruída ao longo do tempo por influência da culinária portuguesa e das comunidades que viviam no Brasil com suas diferentes etnias, e por ingredientes encontrados no país. ${ }^{6}$

Na Europa, eram comuns os cozidos de feijão branco com legumes e carne de porco. Porém, ao chegarem ao Brasil, os cozidos tiveram a substituição do feijão branco, originalmente utilizado, pelo feijão preto, que era mais facilmente encontrado no local. ${ }^{6,7}$

Segundo Elias, ${ }^{6}$ os escravos, por terem sofrido influência da religião muçulmana, não poderiam consumir carne de porco, o que, segundo o autor, colocaria em dúvida a origem da feijoada nas senzalas. Já de acordo com Câmara Cascudo, ${ }^{5}$ a farinha de mandioca e o feijão preto, que começava a ter destaque na mesa brasileira no século XVIII, eram a composição básica da alimentação dos escravos no Rio de Janeiro.

Nas fazendas de famílias mais abastadas, a alimentação do escravo era composta de canjica, feijão preto, toucinho, carne seca, farinha de mandioca, laranjas e bananas, o que podemos considerar, talvez, como os primórdios da feijoada como a conhecemos hoje. Porém, a prática de cozinhar alimentos juntos, como feijão e carnes, parece ser resultado da influência dos portugueses, já que nem os índios nem os africanos costumavam cozinhar os alimentos misturados. ${ }^{5}$

Recentemente, unindo ritmo e comida, várias agremiações no Rio de Janeiro veem suas quadras se encherem com apreciadores do samba e da feijoada. É o caso do Cacique de Ramos, fundada em 1961, que realiza em sua quadra uma roda de samba acompanhada de feijoada, todo o terceiro domingo do mês.

No presente estudo, buscou-se compreender o contexto sociocultural da relação da feijoada com o samba no Cacique de Ramos, que se constituiu em referência na defesa do samba de raiz e do partido alto, tornando-se um ícone emblemático do subúrbio no Rio de Janeiro.

\section{Metodologia}

Para alcançarmos o propósito da investigação, aproximamo-nos da Hermenêutica de Profundidade (HP) de Thompson. ${ }^{8}$ A HP consiste na compreensão dos sentidos atribuídos ao objeto estudado, que podem ser revelados por meio da interpretação de falas, ações, textos e demais formas simbólicas e da maneira como estas são transmitidas e recebidas pelos sujeitos. ${ }^{8}$

A aplicação da HP se baseia no desenvolvimento de fases, que não são necessariamente consecutivas. A análise sócio-histórica consiste em estudar o ambiente, as instituições, estruturas sociais e os campos de interação em que as formas simbólicas são produzidas/transmitidas; análise formal implica os procedimentos de organização e tratamento do material empírico, a partir de referencial analítico indispensável para compreender o campo-objeto; e análise interpretativa, que 
é a análise propriamente dita, ou seja, a compreensão das formas simbólicas, também pautada em diálogo com a literatura. Nessa perspectiva, cada uma dessas fases corresponde a movimentos da pesquisa, que devem ocorrer de forma complementar e articulada. ${ }^{8}$

Para este estudo, optamos por recortar a análise sócio-histórica (ASH) com a finalidade de revelar a potencialidade da mesma para a compreensão do contexto sociocultural do fenômeno estudado: a feijoada na roda de samba do Cacique. Buscou-se a reconstrução das condições sociais, culturais e históricas nas quais, textos, falas ou ações (formas simbólicas) são produzidas e transmitidas entre os sujeitos do campo-objeto estudado. ${ }^{8}$

O delineamento da ASH levou em consideração os elementos que devem fazer parte de seu escopo, a partir de uma releitura de Thompson ${ }^{8}$ e de uma adaptação da Análise de Conteúdo Temática de Bardin. ${ }^{9,10}$

Dessa forma, a ASH foi definida como um tema e os elementos que a compuseram, como categorias analíticas, a saber: o ambiente: espaço e tempo, pois as formas simbólicas são transmitidas e recebidas dentro de um contexto específico; o campo e suas interações, um conjunto de situações, posições e trajetórias que definem ou facilitam a relação entre os sujeitos e as instituições; as regras, convenções e esquemas que fazem parte das atividades cotidianas e visam à difusão e manutenção da cultura; recursos e meios pelos quais as mensagens transmitidas são codificadas ou decodificadas para que façam sentido para os sujeitos envolvidos. ${ }^{8}$

A análise evidenciou sentidos que foram aglutinados com vistas à interpretação e redação final do texto.

Com vistas à obtenção de dados empíricos que subsidiassem todas as análises, inicialmente, a pesquisadora principal estabeleceu contato com membros da diretoria da agremiação, a fim de obter permissão para a realização do trabalho de campo. Posteriormente, frequentou as rodas de samba com feijoada, todo terceiro domingo do mês, durante o período de um ano.

Coube ao pesquisador estar atento às situações e interações que aconteciam no campo para poder compreender o fenômeno e não isolar as formas simbólicas do contexto de sua produção e transmissão.

Partimos da premissa de que o sentido de um fenômeno é compreendido por referência ao seu contexto e vice-versa, que é também partilhado entre o todo e a parte e entre pesquisador e sujeitos do estudo. ${ }^{9}$

Assim, foi realizada observação atenta com foco nos aspectos do espaço e do cenário da agremiação; nas pessoas que frequentam os eventos ali realizados, nos moradores e comerciantes locais; nas interações cotidianas entre as instituições do entorno e as que se desenrolavam no decorrer dos eventos; as regras e transgressões; os rituais e crenças. Além da observação, foram 
realizadas entrevistas livres com pessoas que frequentavam as rodas de samba e com comerciantes e moradores do entorno do Cacique de Ramos.

A fim de complementar e aprofundar os dados aplicou-se, ainda, um roteiro com questões centrais de interesse do estudo a sujeitos-chave. Essas entrevistas formais foram marcadas em local e horário conveniente ao entrevistado.

Os dados de observação foram registrados em caderno de campo e as entrevistas foram gravadas (e também registradas em caderno de campo, quando não foi possível a gravação em áudio). Não foi estabelecido número de eventos a serem observados ou entrevistas a serem realizadas, sendo estes considerados suficientes quando se atingiu a redundância de sentidos apreendidos para responder aos objetivos do estudo.

O mergulho da pesquisadora no campo possibilitou elaborar internamente ideias de familiaridade e estranhamento. O momento de familiarização se deu pelo encontro com o objeto, pela impregnação e naturalização. Passado esse momento, foi necessário o exercício do olhar distanciado e estranho. Compreender um grupo social "por dentro" e "de fora" é também um requisito para entender as lógicas que lhe escapa. ${ }^{11}$

O estudo é um recorte da pesquisa intitulada "Simbologia e significação da comida no contexto do samba carioca”, aprovada pelo Comitê de Ética em Pesquisa do HU/UFRJ parecer número 862.993, de 9 de outubro de 2014.

A autorização, tanto para observação do cenário/contexto quanto para as entrevistas formais e livres, foi expressa por meio de Termo de Consentimento Livre e Esclarecido, recomendado para pesquisas com seres humanos pela Resolução № 466/2013, do Conselho Nacional de Saúde. ${ }^{2}$ A pesquisadora indagou sobre quaisquer dúvidas que cada participante pudesse ter e as esclareceu antes do início da entrevista/observação. Foi garantido o anonimato dos sujeitos que participaram do estudo.

\section{Resultados}

O ambiente espacial e temporal

\section{Cacique de Ramos e os bairros de Ramos e Olaria}

O Cacique de Ramos é uma agremiação de samba que foi criada no dia 20 de janeiro de 1961, mesma data em que se comemora São Sebastião, o padroeiro da cidade do Rio de Janeiro e também do bloco. Desde sua criação ocupa local cativo na Rua Uranos, uma das principais da região da Leopoldina. Contudo, ironicamente, o Cacique de Ramos não se localiza no bairro de Ramos, mas sim, em Olaria, estando próximo à divisa entre os dois bairros. 
Por serem bairros vizinhos, Ramos e Olaria possuem características bem semelhantes. Fazem parte da Leopoldina, parte do subúrbio carioca, região mais afastada do centro, que conta com bairros antigos, que contribuíram com a história do samba, e tem grande destaque e valor para os movimentos culturais no Rio de Janeiro. ${ }^{13}$

No Rio de Janeiro, o termo subúrbio é comumente utilizado para designar os bairros atendidos pela malha ferroviária e onde reside a parcela financeiramente desfavorecida da população da cidade. ${ }^{14}$ Dessa forma, o subúrbio carioca, cujos bairros fazem parte da zona norte da cidade, são todos "cortados" pela "linha do trem", divididos em dois lados nem sempre iguais. Madureira, Méier, Engenho Novo, Engenho de Dentro, Del Castilho, Pilares, Barros Filho, Rocha Miranda, Jacarezinho, Cascadura e bairros da Leopoldina, como Olaria, Penha, Ramos, Bonsucesso e Brás de Pina..$^{15}$

A origem do bairro de Ramos remonta à chegada da ferrovia em 1886, mais precisamente a Estrada de Ferro do Norte, futura Leopoldina. A linha do trem precisava passar por dentro de uma propriedade, que havia pertencido ao capitão Luiz José Fonseca Ramos, e seus filhos só permitiram mediante a construção de uma estação no local, que foi batizada Parada do Ramos. Com isso, Ramos começou a ganhar saneamento e urbanização. ${ }^{16}$ A década de 1910 foi uma das mais importantes para o bairro, pois Ramos foi deixando para trás o status de vila rural e se tornando mais metropolitano.

Em 1914, foi inaugurada a primeira sala de cinema da região da Leopoldina, o Cinematógrafo Ideal, localizado na Rua Uranos, a principal via do bairro até hoje. Nesse mesmo ano, foi criado o Teatro Ramos Clube. Outros surgiram nos anos que se seguiram, como o Cine Ramos, o Rosário, o Cinema Bonsucesso, o Cine Leopoldina, o Paraíso, o Mauá e o São Pedro, que serviram como principal meio de entretenimento dos residentes, integrando os "dois lados", separados fisicamente pela linha do trem, mas com muito em comum. ${ }^{17}$

Ramos também era o único bairro na extensão da via férrea que possuía uma praia, elevando seu encanto. Conhecida por "Copacabana dos Subúrbios", a praia de Ramos, hoje imprópria para o banho devido à poluição da Baía de Guanabara, inspirou muitos sambas, como o famoso "Praia de Ramos" (de autoria de Ivany Miranda, Oswaldo Melo e Afranio Melo, gravado por Carlos Alberto de Oliveira, o Dicró, em 1980), que tratava, com humor cômico e pitoresco, um domingo na praia do bairro.

Olaria tem, aproximadamente, 58 mil habitantes e ampla cobertura de abastecimento de água, energia elétrica e saneamento básico. O Índice de Desenvolvimento Humano (IDH) é de 0,78, e 20,17\% da população possui renda proveniente de programas de transferência de renda governamentais. Já Ramos, possui IDH de 0,60 e 20\% de seus moradores contam com $50 \%$ de sua renda proveniente de programas de transferência de renda governamentais. ${ }^{18}$ 
É uma região densamente povoada, com muitos estabelecimentos comerciais de todos os portes, desde grandes redes de supermercados até armarinhos com décadas de existência no mesmo local. Ainda que contemplem uma grande quantidade de estabelecimentos comerciais, ambos os bairros conservam forte característica residencial. Grande parte de suas ruas são estritamente residenciais, com casas, vilas e pequenos prédios, onde é frequente encontrarmos vizinhos, conversando nas calçadas, sentados nos portões em suas cadeirinhas, e crianças, brincando com pipas e bolas. Diversas praças arborizadas, com brinquedos para as crianças, bancos, mesinhas, quiosques, barraquinhas de comida nas esquinas e bares com décadas de existência contribuem para uma atmosfera aparentemente tranquila e acolhedora. Muitos de seus moradores nasceram e foram criados nesses bairros, o que os torna a residência de famílias inteiras, que conservam um carinho muito grande pelo lugar.

Nos primórdios, o samba na região ainda não era exatamente o que chamamos de samba, mas sim um Carnaval de rua muito forte. Os primeiros clubes criados na década de 1910 - Prontos de Ramos, Ameno Heliotropo e Endiabrados de Ramos - foram os precursores de famosos blocos carnavalescos entre os anos 1930 e 1950, como o Sai como Pode, o Razão de Viver, o Paixão de Ramos e o Paz e Harmonia, além daquele que teve o maior destaque na região, o Recreio de Ramos, cujo nome foi substituído por Cacique de Ramos pelos irmãos Ubirajara, Ubirany e Ubiracy, Walter Tesourinha e Aimoré do Espírito Santo.

Havia também o Bafo da Onça, grande "rival" do Cacique na época, que causava verdadeiras "batalhas" entre os foliões dos dois blocos. ${ }^{13,16}$ No Carnaval de 2015, aconteceu um fato inédito, Cacique de Ramos e Bafo da Onça, rivais no Carnaval de rua do subúrbio, desfilaram juntos pela primeira vez na avenida Graça Aranha, no Centro da cidade.

As tradicionais fantasias de índio, remetendo ao índio americano, que os componentes do Cacique vestiam, foram uma grande novidade na época e delas foi que derivou as cores que representam até hoje a agremiação: branco, preto e vermelho. No começo, até os membros da diretoria se vestiam de índios. Porém, a partir de 1964, os diretores passaram a desfilar de bermuda e camisa listrada com as cores do bloco e a cabeça do cacique nas costas. ${ }^{13}$

\section{"Uma agremiação a serviço da música popular brasileira"}

A frase acima está pintada, em destaque, na parede interna da quadra. Demonstra a intenção de reforçar um valor que é necessário para colocar o Cacique de Ramos em evidência, no contexto do samba. Estar a "serviço da música popular brasileira" é uma forma de distinção, manutenção e resistência do local.

A quadra do Cacique de Ramos ocupa um grande terreno na principal rua da região, onde há intenso fluxo de carros, ônibus, vans e pedestres. Densamente habitado, com casas que remontam à 
criação do bairro e também prédios mais recentes, o entorno também conta com grande variedade de estabelecimentos comerciais, desde armazéns, lojinhas de roupa, papelarias, bares e oficinas mecânicas, até mercados de grandes marcas.

Ao entrar na quadra do Cacique, observam-se fotos dos primeiros desfiles, que ocorriam na avenida Rio Branco, expostas à apreciação do público. O terreno tem um amplo espaço descoberto, onde estão plantadas duas tamarineiras, e uma parte coberta, onde são montadas as mesas e o palco para as rodas de samba, além do bar, da cozinha, banheiros e instalações dos funcionários e diretoria.

As flâmulas penduradas na quadra ostentam fotos de grandes nomes, que passaram pelo Cacique e, também, da imagem de São Sebastião. Mas a imagem do Santo Padroeiro, oferecida pelo arcebispo da cidade do Rio de Janeiro, fica exposta logo na entrada, em destaque e sob a sombra de uma amendoeira, protegida por uma cúpula de vidro. Também, sob uma cúpula de vidro, e ao lado de uma das tamarineiras, encontra-se uma imagem de São Jorge.

Desde sua fundação grandes nomes do samba carioca foram revelados no Cacique, como Zeca Pagodinho, Almir Guineto, Arlindo Cruz, Jorge Aragão e o grupo Fundo de Quintal. Ainda hoje o Cacique de Ramos é muito respeitado no mundo do samba, tendo sido enredo da Mangueira, que contou a história do bloco no Carnaval de 2012. O Cacique ainda inspira outras agremiações. O presidente Bira foi homenageado por um bloco em Caxias, em 2016; mesmo ano em que a escola de samba Arrastão de Cascadura, pertencente à série C, trouxe um enredo intitulado "O Arrastão anuncia: Todo dia é dia de Cacique de Ramos!". Também o bloco comandado pelo cantor Elymar Santos convidou o presidente para animar os folióes. ${ }^{19}$

Essa deferência, com que o Cacique de Ramos é tratado por outras agremiações, parece revelar que ele ocupa uma posição de destaque no mundo do samba. É o que, de acordo com Bourdieu, ${ }^{20}$ podemos chamar de distinção social, um capital simbólico adquirido e que o distingue de outras agremiações.

Outro fato que comprova a importância do Cacique, é que a estação do sistema de transporte BRT (Bus Rapid Transit) mais próxima à quadra foi identificada com o nome da agremiaçãoa ${ }^{21}$

Havia a preocupação de que a quadra precisasse ser desapropriada para a conclusão da obra desse corredor exclusivo de ônibus, mas, para o alívio de todos, o traçado da via foi modificado e poupou a agremiação, além de casas e comércios do bairro. ${ }^{22}$

a O sistema BRT Transcarioca consiste em uma via exclusiva de ônibus, com estações que interligam o Aeroporto Internacional Tom Jobim (Galeão), na Ilha do Governador, zona norte do Rio de Janeiro, ao terminal Alvorada, na Barra da Tijuca, zona oeste da cidade, percorrendo um total de $39 \mathrm{~km}$ e interligando 27 bairros, com paradas em 47 estações ao longo da via. ${ }^{21}$ 
É possível que a posição que o Cacique ocupa dentro do imaginário do samba, de ser uma agremiação tida como mantenedora das tradições, transmitidas de maneira simbólica, mas que se tornam capital social, seja o que contribui para que a agremiação obtenha algumas conquistas, fazendo com que se perpetue a distinção do Cacique de Ramos nesse contexto. ${ }^{20}$

Atualmente, por meio do uso da via expressa, participantes de outros bairros atendidos pelo sistema contam com mais facilidade e rapidez para chegar ao Cacique. Após a inauguração do BRT, a diretoria percebeu um aumento de frequentadores nos eventos. “(...) Isso aí foi uma mão na roda pro povo frequentador (...). Esse BRT aí foi a melhor coisa! E a estação é Cacique de Ramos”. Há um orgulho na fala do entrevistado, não somente pelo fato da agremiação ter sido homenageada com o seu nome na estação, mas, também, pela melhoria do acesso.

O movimento de arte de rua exalta a presença do Cacique de Ramos com grafites de índios estampados nos muros do bairro, que remetem às fantasias utilizadas pelos seus seguidores na época dos desfiles de Carnaval, na avenida Rio Branco, no centro da cidade, revelando o valor atribuído à agremiação por diferentes grupos da sociedade carioca.

Na internet, o Cacique de Ramos também se destaca. Em uma simples busca por seu nome em sites de pesquisa na rede, é possível visualizar cerca de 540 mil resultados, dentre os quais sua página oficial e outras páginas que trazem sua história e eventos, matérias de jornais, vídeos e fotos.

Em 2011, a agremiação recebeu a medalha Tiradentes, concedida pela Assembleia Legislativa do Rio de Janeiro, em homenagem aos seus 50 anos de fundação, sendo reconhecido como responsável por manter a tradição do Carnaval carioca e como baluarte da carreira de notórios nomes da música popular brasileira. Essa premiação torna legítima e capitaliza a posição do Cacique dentro do contexto do samba, porque o eleva a uma classe de destaque nesse universo, incorporando um símbolo de poder, de autoridade, de distinção social e cultural. ${ }^{20}$

A quadra já recebeu a visita de políticos, como o prefeito do Rio de Janeiro, atores e atrizes famosos e até autoridades religiosas, como o arcebispo da cidade. Todas essas visitas foram devidamente documentadas em fotos e vídeos disponibilizados no site oficial da agremiação, ${ }^{23} \mathrm{o}$ que aumenta a visibilidade da agremiação e legitima sua importância.

O Cacique é uma opção de entretenimento aos domingos. Moradores ressaltam a importância para a imagem dos bairros de ter um ícone do samba carioca como "morador". Segundo alguns entrevistados, o bairro tem mais a oferecer, podendo "ser reconhecido por uma coisa alegre, que é o samba”. É um ponto positivo para uma região, que frequentemente é citada em páginas policiais de jornais e na televisão, pela violência, que pesa e marca a vida das pessoas que lá residem. ${ }^{24}$ 


\section{O campo e suas interações}

A convivência com a vizinhança, apesar de considerada pacífica, às vezes gera algum atrito, especialmente devido ao som alto proveniente da quadra. Alguns moradores relataram se sentirem incomodados com o barulho. Muitas pessoas aproveitam o domingo, tido como um dia reservado para o descanso, para dormir até tarde, ficar em casa com a família, assistindo algum filme na TV. Por ser aberta e não possuir isolamento acústico, o som vindo da quadra do Cacique pode ser ouvido da rua, o que leva às reclamações com o barulho.

Um membro da diretoria entrevistado minimiza a questão e afirma que diz para os moradores que reclamam do som: "Companheiro, você comprou essa casa (...) quando tu comprou, tu não viu que aqui tinha um bloco de carnaval? Por que não comprou uma casa do lado do cemitério? Lá é 'silencinho', nenhum barulhinho... (...) ao invés de tu reclamar, vem pra cá pra festa!”. Nesse sentido, de acordo com o entrevistado, para morar próximo à quadra, é preciso ter flexibilidade, disposição para suportar o barulho e gostar de samba, revelando que os vizinhos é que têm que se conformar e se adaptar e não a agremiação. Foi relatado ainda, pelo membro da diretoria, um episódio em que um morador fez uma reclamação mais contundente sobre o barulho excessivo. Como forma de negociação, a agremiação ofereceu acesso livre nos dias de evento, com mesa e bebidas ofertadas gratuitamente ao morador, que desde então não fez mais nenhuma objeção ao som proveniente do Cacique. Essa passagem nos revela possíveis formas de interação em função dos interesses coletivos e individuais. Valendo-se de sua condição de morador, ao reclamar seu direito ao silêncio e descanso, o vizinho obteve um benefício. Ao mesmo tempo, o Cacique, dispondo do poder de abrir suas portas e oferecer gratuitamente bebidas, livrou-se de um possível conflito. Essa forma de interação e negociação, entre a instituição e o sujeito, demonstra a assimetria "em termos de distribuição e acesso a recursos, poder, oportunidades e possibilidades de realização" (p. 367). ${ }^{8}$

Os carros estacionados nas calçadas e, muitas vezes, nos portões de casas e prédios do entorno da quadra também geram reclamação.

Vizinha à quadra existe uma Igreja Pentecostal Assembleia de Deus. Segundo um entrevistado, alguns membros da Igreja reclamavam que, devido aos inúmeros carros estacionados na calçada do prédio, havia certa dificuldade na saída do culto, que também ocorre aos domingos. O problema foi sanado pelo próprio Cacique, que contratou um segurança para impedir o estacionamento de carros em frente à Igreja. Nesse sentido, todo esforço deve ser feito para garantir uma convivência mais harmoniosa e preservar os interesses de cada instituição.

Quando chega à noite, do lado de fora, começam a ser montadas barraquinhas, vendendo os mais diversos produtos: balas e doces, bebidas, cachorro-quente, churrasquinho, que são comercializados até o final da noite, quando acaba o samba no Cacique. Porém, o que faz a alegria de muitos também é o incômodo de outros. Alguns moradores relatam que após a retirada das 
barraquinhas, o lixo jogado indevidamente pelas calçadas gera mau cheiro e colabora para o entupimento dos bueiros, o que é especialmente temerário numa região que sofre com alagamentos em dias de chuvas fortes.

Esse comércio paralelo, fora da quadra, é motivo de irritação na agremiação, evidenciada na fala do entrevistado, pois, provavelmente, compete com a feijoada e os demais alimentos e bebidas vendidos no Cacique:

Isso aí nós não temos nada, nada a ver com o que acontece lá fora, infelizmente... Nós não podemos tirar eles, nós não botamos, mas nós também não podemos tirar, isso é problema da prefeitura! Existe reclamação porque a gente acaba onze e meia aqui e o pessoal sai daqui pra ir tocar lá na barraca (...) então fica até 2 horas da manhã, tem reclamação, mas a gente não pode fazer nada... A rua é a rua! Botou do portão pra fora...

O comércio formal local parece não ser afetado pelos eventos na quadra. Por acontecer aos domingos, grande parte dos estabelecimentos está fechada ao público no momento da feijoada e das rodas de samba. Portanto, os comerciantes não tecem críticas ao Cacique, pelo contrário, muitos são moradores do bairro e de bairros próximos e já frequentaram alguma vez a agremiação.

\section{As regras, convenções e esquemas}

\section{Cacique e a tamarineira: sombra, misticismo, proteção}

Ao chegar à quadra, uma das tamarineiras recebe o visitante com sua imponência e sombra. Envolta em misticismo, a árvore chegou a pegar fogo, mas resistiu e voltou a crescer. O incidente se deu após um churrasco na quadra, quando depositaram restos das brasas de carvão aos pés da árvore, que acabou se incendiando, mas depois voltou a se recuperar.

Segundo o membro da diretoria, a pessoa que tocar no tronco da tamarineira receberá boas vibrações, citando como exemplo: “(...) o cara faz uma música, um compositor, se não passar ali com a música debaixo da tamarineira não dá certo, não faz sucesso”. Citou um fato que ocorreu quando o grupo Fundo de Quintal fazia as escolhas de sambas para compor seus CD's na quadra do Cacique:

(...) um elemento, ele veio aqui (...) Então esse cara chegou aí... - Pô, meu irmão, eu tô com um samba aqui... - Espera tua vez aí. Como é o nome da música? - Tudo por 1,99. Pô meu irmão, tenho que entrar nesse CD. Eu tenho que estar nesse CD porque esse meu samba vai fazer sucesso!. Ai eu falei: Faz o seguinte, vai lá pra baixo da tamarineira, ali, e pede pros Orixás lá pra botar o teu samba na parada! Você é forte? Pede lá, faz um pedido, promete qualquer coisa, de repente tu consegue.... Ai ele trouxe um CD, encostou na árvore ali, encostou o papel da letra... Ai, resumindo, chegou a vez dele, ele foi lá pra cantar, botou o CD no som ali. (...) Ai, quando chamou o Fundo de Quintal, pra pegar os instrumentos pra tocar e ele cantar a música ali ao vivo, junto com o próprio Fundo de Quintal (...) entrou no CD, gravou... Ele vem aqui, toma bênção na minha mão, faz isso, faz aquilo, faz tudo, me agradece, me abraça, me beija, faz tudo que é possível! 
A música "Tudo por 1,99” foi gravada pelo grupo Fundo de Quintal, lançada em 2003, no CD Festa para a comunidade.

Ainda com relação ao misticismo, apesar da presença de imagens de santos católicos, como São Sebastião e São Jorge, o Cacique de Ramos também cultua Orixás de religiões africanas.

Tanto nas duas tamarineiras, plantadas no terreno, como no muro, existem patuás, relacionados a Oxóssi. Oxóssi é um orixá conhecido na Umbanda como caçador e protetor das matas, sincretizado no catolicismo a São Sebastião. Segundo o Núcleo Umbandista São Sebastião, Oxóssi é representado no plano terrestre por caboclos, índios e guerreiros africanos. ${ }^{25}$ Dessa forma, podemos perceber a relação desses símbolos no interior da quadra do Cacique: Oxóssi, sincretizado a São Sebastião, o santo do dia da fundação da agremiação, santo protetor das matas (os patuás estão nas árvores) e seus enviados seriam caboclos e índios. Somente dois membros da diretoria podem retirar e recolocar os patuás, pois foram "preparados" para isso.

Com relação a São Jorge, anualmente se realiza uma festa na quadra em homenagem ao Santo Guerreiro. Na Umbanda, São Jorge é Ogum, um orixá protetor contra as guerras e as demandas espirituai. ${ }^{26}$

Além disso, também foi revelado durante entrevista que existe um espaço dedicado à Zé Pelintra, entidade que aparece nos cultos na região sudeste do Brasil, simbolizando um "malandro", considerado por alguns como espírito protetor de bares e locais de jogos. ${ }^{27}$

A tamarineira já virou um símbolo de proteção dentro da agremiação, tamanho o simbolismo que ela carrega. Aos pés da árvore, foi colocada uma placa com a seguinte citação: "Todas as pessoas que aqui passarem, forem boas de coração e tiverem dotes especiais, colherão frutos." É possível ver diversas pessoas, tocando e reverenciando a árvore ao chegar ou sair do local. O culto à tamarineira se iniciou e se perpetuou, dentro do grupo, com o renascimento da árvore após o incêndio.

Conforme aponta Thompson ${ }^{8}$ sobre transmissão e recepção das formas simbólicas, as regras e crenças são transmitidas em falas e gestos, que se repetem e são interpretados, nesse caso, como um sinal de boa sorte, bênção e manutenção sociocultural do grupo.

\section{Os recursos e meios de transmissão simbólica}

\section{A feijoada no Cacique de Ramos}

Antes de se iniciar a tradição da feijoada, no ano de 2011, o Cacique de Ramos servia sopa de ervilha. Porém, como a quadra ainda não possuía cobertura, em dias chuvosos, poucas pessoas apareciam no local, sobravam grandes quantidades de sopa, que eram levadas para casa pelos 
próprios membros ou distribuídas entre as pessoas da rua, para evitar o desperdício. Nesse período, já se falava em fazer uma feijoada, porém sem a cobertura adequada do local, o risco de prejuízos era muito grande.

Em 2011, com a ajuda de alguns políticos locais, a reforma e colocação da cobertura da quadra foram obtidas. Assim, o Cacique voltou a servir um acompanhamento a sua já conhecida roda de samba. A sopa de ervilha foi posta de lado e substituída pela feijoada, já que, segundo um entrevistado: “(...) a feijoada é tradição, tem em tudo quanto é lado! Tem até campeonato de feijoada..."

Ao assumir a feijoada como prato principal de sua roda de samba, o Cacique incorpora um elemento simbólico para potencializar sua imagem de mantenedora de tradições, uma vez que se atribui à feijoada simbolismos relacionados à cultura alimentar e identidade brasileira. ${ }^{6}$

Todo domingo é dia de samba no Cacique, com sua tradicional roda de samba, começando às 17 horas. Porém, no terceiro domingo de cada mês ocorre a feijoada, que atrai os amantes do samba e apreciadores do prato. Neste dia, em especial, a agremiação abre seus portões às 13 horas. Os visitantes podem alugar uma mesa, com quatro cadeiras, por $\mathrm{R} \$ 15,00$ e pagar $\mathrm{R} \$ 20,00$, por pessoa, pela feijoada (valores referentes ao ano de 2015).

O ambiente é diversificado: homens, mulheres, jovens e idosos, até mesmo crianças, podem ser vistos no interior da quadra. São frequentadores assíduos, visitantes novos, de bairros vizinhos, convidados da Diretoria e também oriundos de outros Estados. No decorrer do domingo, vários ônibus podem ser vistos, trazendo pessoas em busca de muita animação, de música e comida. Enquanto alguns se sentam nas mesas postas sob a cobertura da quadra, outros se encostam nas paredes ou permanecem de pé pelo local. Dois bares fornecem bebidas das mais variadas, alcoólicas e não alcoólicas, que podem ser compradas. A cerveja, sempre bem gelada, e os refrigerantes são a preferência da maioria.

Se no domingo a feijoada já está pronta para ser servida, isso é fruto de um trabalho que se inicia na sexta-feira com a compra dos ingredientes, segundo o responsável pela organização da feijoada, desde 2012.

Ao todo são $140 \mathrm{~kg}$ de carne, entre linguiça, carne seca, lombo e costelinha. Desses, $20 \mathrm{~kg}$ são divididos entre pé, orelha e rabo de porco, além de $30 \mathrm{~kg}$ de toucinho, para fazer o torresmo que acompanha a feijoada. De feijão, são $30 \mathrm{~kg}$, e mais $30 \mathrm{~kg}$ de arroz, $25 \mathrm{~kg}$ de farinha de mandioca, 130 molhes de couve e, aproximadamente, $20 \mathrm{~kg}$ de laranja para completar. Essas quantidades são planejadas para uma média de 400 a 500 pessoas.

O preparo se inicia na própria sexta-feira, quando um responsável coloca as carnes de molho, em água, para a retirada do sal. No sábado, uma equipe de quatro pessoas vai até a cozinha, instalada na quadra, para iniciar o preparo das carnes e o cozimento do feijão. Segundo o entrevistado, a 
feijoada servida no Cacique "é uma feijoada nobre, com todas as carnes separadas". A agremiação reconhece que nem todas as pessoas apreciam todos os tipos de carnes utilizadas na confecção do prato. Dessa forma, as pessoas podem escolher do que se servir.

A organização para que a feijoada seja saborosa e servida de forma impecável é grande. Os funcionários uniformizados estão acostumados a lidar com o público. O tempo de preparo é calculado para que às 13 horas já estejam montados os tachos com os componentes que fazem parte da feijoada.

A agitação que antecede a abertura dos portões é grande: montagem das mesas e cadeiras, teste de som, arrumação da mesa da feijoada, ao mesmo tempo que alguns membros já se posicionam próximos à entrada para aguardar os visitantes. Quem visita o Cacique se sente seguro por lá: funcionários com detectores de metais tentam impedir que alguma pessoa mal-intencionada consiga entrar na quadra.

Logo que a quadra abre, os visitantes começam a chegar, principalmente famílias, que vêm para fazer da feijoada do Cacique o seu almoço de domingo. Aos poucos, o local vai sendo ocupado por mais gente, até que, por volta das 15 horas, a quadra já está repleta, com sons que mesclam o samba e as conversas animadas entre os frequentadores.

A feijoada é servida fartamente até por volta das 17 horas, quando é retirada para dar lugar aos petiscos que acompanham as rodas de samba, como pastéis, batata frita e caldos, mas a animação continua até a noite. Há dias em que por volta de 19 horas já não existe mais espaço para ninguém no interior da quadra. A fila que se forma para entrar dá a volta no quarteirão. Segundo o entrevistado, o Cacique está providenciando roletas para controlar o acesso à quadra, para que, conforme os frequentadores forem deixando o local, quem está do lado de fora possa entrar com mais tranquilidade.

Todo o preparo e a distribuição da feijoada são de responsabilidade de uma empresa terceirizada. Apesar de se diferenciar do que comunmente ocorre em outras agremiações, de serem pessoas da comunidade as responsáveis pelo preparo da feijoada, os frequentadores do Cacique parecem não saber ou não se importar com isso. Esse fato poderia ser visto como um aspecto contrário ao sentido de tradição perpetuado pelo Cacique, mas, provavelmente, não traz prejuízo,pois existem outros símbolos mais notórios que sustentam a tradição social e cultural.

Mesmo moradores que não gostam de samba, frequentam ou já frequentaram a quadra por causa da feijoada. E muitos têm vontade de ir algum dia para experimentar o prato, pois conhecem alguém que experimentou e elogiou.

A ideia de que o samba e a comida são elementos que não podem ser separados parece ser recorrente entre os frequentadores do Cacique. Porém, de acordo com um entrevistado, "depois que 
pegou essa mania de feijoada, é só feijoada”. Nesse sentido, alguns elementos parecem contribuir para a difusão da feijoada no samba e também no Cacique. Segundo alguns entrevistados, assim como o samba, a feijoada é associada à cultura negra no Brasil e simboliza a culinária brasileira; é muito apreciada e, por isso, atrai muitas pessoas; é considerada uma “comida pesada”, necessária para aguentar o ritmo intenso do samba; remete à fartura, sendo própria para grandes eventos, onde a comensalidade se faz presente. Apesar de ser considerada "pesada", até crianças podem comer, se for oferecido às mesmas apenas o feijão sem as carnes.

\section{Conclusão}

Se outrora o Cacique de Ramos era seguido por dezenas de milhares de 'índios' em seus desfiles na avenida Rio Branco, hoje já não se pode dizer o mesmo. Para um entrevistado, o público frequentador do Cacique, hoje, é diferente do de sua época áurea; é um público que "não quer brincar carnaval", um público que "gosta de roda de samba, de Zeca Pagodinho, Almir Guineto" .Essa mudança na forma como é celebrado o Carnaval carioca atualmente, com blocos seguidos por multidões, na orla ou no Centro da cidade, mas que não pertencem a nomes tradicionais do samba no Rio de Janeiro, pode explicar o declínio que o bloco Cacique vivenciou nos últimos anos. No entanto, embora o bloco já não tenha tantos seguidores nos dias de folia, as rodas de samba enchem a quadra todos os domingos.

A feijoada, que é aguardada ansiosamente pelos frequentadores todo mês, coroa a roda de samba e agrega simbolismos ao Cacique de Ramos. Serve ainda como recurso de transmissão das formas simbólicas, contribuindo com a manutenção material e simbólica da agremiação.

A religiosidade, assim como o culto à tamarineira, também pode ser interpretada como expressão de manifestação das regras e crenças que, de certa forma, unem as pessoas. As interações entre a agremiação e os frequentadores, os vizinhos da quadra, moradores do bairro e comerciantes revelam as relações de poder existentes e a transmissão de valores que se desenvolvem entre os sujeitos.

As entrevistas realizadas, bem como a observação e a confecção do diário de campo possibilitaram à pesquisadora desvendar alguns aspectos dessa agremiação, as interações entre os sujeitos, entre os sujeitos e o campo; a análise e interpretação desses dados permitiram um maior entendimento das relações que permeiam o samba e a feijoada no Cacique de Ramos.

O universo do samba no Rio de Janeiro abre uma gama de possibilidades de estudos, que devem ser explorados a fim de melhor conhecer a sua formação e papel dentro da sociedade, como elemento transmissor e mantenedor de tradições. 


\section{Referências}

1. Fontenelle AL. O samba e a culinária mineira: análise etnográfica de um samba de Toninho Geraes e Pulinho Rezende. O gosto da música: $9^{\circ}$ Encontro Internacional de Música e Mídia; 18-20 set. 2013; São Paulo. Escola de Comunicação e Arte, Universidade de São Paulo.

2. Diniz A. Almanaque do samba: a história do samba, o que ouvir, o que ler, onde curtir. 2. ed. Rio de Janeiro: Jorge Zahar; 2006.

3. Napolitano M, Wasserman MC. Desde que o samba é samba: a questão das origens no debate historiográfico sobre música popular brasileira. Revista Brasileira de História 2000; 20(39):167-189.

4. Sgarioni M. A música da minha Terra. Revista Continuum. Fundação Itaú Cultural; 2010.

5. Cascudo LC. História da alimentação no Brasil. 2 ed. Belo Horizonte: Itatiaia; 1983.

6. Elias R. Feijoada: breve história de uma instituição comestível. Nossa História 2004; 4: 33-40.

7. Carneiro HS. Comida e sociedade: significados sociais na história da alimentação. História: Questões e Debate 2005; 42:71-80.

8. Thompson JB. Ideologia e cultura moderna: teoria social crítica na era dos meios de comunicação de massa. Petrópolis: Vozes; 2011.

9. Schwandt TA. Três posturas epistemológicas para a investigação qualitativa. In: Denzin NK, Lincoln YS. O planejamento da pesquisa qualitativa: teorias e abordagens. Porto Alegre: Artmed; 2006. p. 193-217.

10. Bardin L. Análise de conteúdo. Lisboa: Edições 70; 1977.

11. Laplantine F. Aprender antropologia. São Paulo: Brasiliense; 2000.

12. Brasil. Comissão Nacional de Saúde. Resolução nº 466, de 12 de dezembro de 2012. Diário Oficial da União no 12, 13 jun. 2013.

13. Pereira CAM. Cacique de Ramos: uma história que deu samba. E-Papers; 2003.

14. Soto WHG. Subúrbio, periferia e vida cotidiana. Estudos, Sociedade e Agricultura 2008; 16(1):109-131.

15. Oliveira MP. Soluções e esperanças nas fronteiras da cidade. Caderno Globo Universidade 2013; $1(2) 18-25$.

16. Vianna LF. Geografia carioca do samba. Rio de Janeiro: Casa da Palavra; 2004.

17. Caiafa J, Ferraz T. Comunicação e sociabilidade nos cinemas de estação, cineclubes e multiplex do subúrbio carioca da Leopoldina. Galáxia 2012; 12:127-140.

18. Instituto Brasileiro de Geografia e Estatística. Índice de desenvolvimento social, 2010. [acesso em: 18 out. 2015]. Disponível em: http://portalgeo.rio.rj.gov.br/indice/flanali.asp?codpal=54\&pal=DE SENVOLVIMENTO \%2 0SOCIAL/HUMANO

19. Piscitelli Entretenimentos [Internet]. Elymar Santos lança bloco carnavalesco que terá Ivete Sangalo e Nayra Cezari como madrinha e rainha, 2015. [acesso em: 27 set. 2015]. Disponível em: http://www. piscitellientretenimentos.com/elymar-santos-lanca-bloco-carnavalesco-que-tera-ivete-sangalo-enayra-cezari-como-madrinha-e-rainha/ 
20. Bourdieu P. A distinção: crítica social do julgamento. Porto Alegre: Zouk; 2006.

21. Brasil. Comissão Nacional de Saúde. Resolução no 466, de 12 de dezembro de 2012. Diário Oficial da União no 12, 13 jun. 2013.

22. BRT. Conheça o BRT, 2015 [Internet]. [acesso em: 15 ago. 2015]. Disponível em: http://brtrio.com/ conheca

23. Quintão E. Não deixe nosso bairro morrer, apelam moradores de Ramos. Jornal Extra [Internet] 15 nov. 2011. [acesso em: 10 nov. 2014]. Disponível em: http://extra.globo.com/noticias/rio/naodeixenosso-bairro-morrer-apelam-moradores-de-ramos-3243229.html

24. Cezari N. Emoção e bênçãos nas homenagens a Dom Orani na quadra do Cacique de Ramos, 2012 [Internet]. [acesso em: 27 set. 2015]. Disponível em: http://caciquederamos.com.br/index. $\mathrm{php} / 35$-eventos/eventosoficiais1/83-emocao-e-bencaos-nas-homenagens-a-dom-orani-na-quadrado-cacique-deramos

25. Instituto de Segurança Pública (Rio de Janeiro). ISP divulga dados de UPP's, 2015 [Internet]. [acesso em: 15 ago. 2015]. Disponível em: http://www.isp.rj.gov.br/Noticias.asp?ident=316

26. Núcleo Umbandista São Sebastião. Oxóssi (Ou Odé, ou Mutalambô) - São Sebastião, 2008 [Internet]. [acesso em: 27 set. 2015]. Disponível em: http://www.nuss.com.br/os-orixas/oxossi.html

27. Núcleo Umbandista São Sebastião. Ogum (Orixá protetor contras as guerras, protetor da Umbanda) [Internet]. [acesso em: 27 set. 2015. Disponível em: http://www.nuss.com.br/os-orixas/ogum.html

28. Menez L. Zé Pelintra - Orixás e entidades da umbanda e do candomblé, 2015 [Internet]. [acesso em: 27 set. 2015] Disponível em: https://lilamenez.wordpress.com/category/ze-pilintra/ 
